\title{
Development of a design concept for a prototype transport device using the Design Thinking method
}

\author{
Bartosz Mazurek ${ }^{*}{ }^{1}$, Jarostaw Mamala ${ }^{2}$ \\ ${ }^{1}$ Science and Technology Park, Technologiczna 2, Street, 45-839 Opole, \\ ${ }^{2}$ Faculty of Mechanical Engineering, Opole University of Technology, 45-407 Opole, Mikołajczyka \\ 5 , Poland.
}

\begin{abstract}
The article presents the development of a multifunctional prototype transport device mounted on a towing hook of a passenger car, used to transport motorcycles and light four-wheeled vehicles, based on the Design Thinking method. The device, in its original design, has obtained patent protection from the Patent Office [1]. The use of the device in real road conditions requires the solution of many technical, ergonomic, endurance and functional problems, and in the final phase the implementation of the final device. The authors of the study presented the most important construction works described in terms of the analysis of the key strength nodes of the transport device. The boundary conditions for the weight of the device and the forces acting on the device were based on literature data on the load capacity of hooks used in passenger vehicles, the weight of motorcycles in accordance with the classification, which was verified in the identification tests on the real model, taking into account the height of the front wheel suspension of the transported motorcycle. According to the data analysis, the mass of the transport device should oscillate within $10 \mathrm{~kg}$, and the reference point for the construction work is the prototype model made of s 235 steel with a net weight of $28 \mathrm{~kg}$. On this basis, the work presents simulations of a static load with the determination of stresses in the material, deformation and mass calculation for various design versions. In the final stage, the target construction version, designed from two materials, i.e. steel s235 and aluminium 6081, was compared. As a result of the analysis, the target construction reduced the weight of the transport device by $17 \mathrm{~kg}$.
\end{abstract}

\section{Introduction}

The automotive market is growing year by year, the number of vehicles in use in the world already exceeded 1 billion units in 2015. However, the developing society did not give up the need to use light quadricycles and single-track vehicles, most importantly, the nature of their use has changed. More and more often users of two-wheeled vehicles and motorcycles choose this means of transport for recreational purposes. The numbers speak for it, as the potential of the automotive market increases and the number of newly registered motorcycles

\footnotetext{
${ }^{*}$ Corresponding author: b.mazurek@pnt.opole.pl
} 
in the European Union increased by 8\% in 2019 and amounted to 1,079,524 units compared to 2018 according to the European Association of Motorcycle Manufacturers (ACEM) (fig. 1.). Italy remains the largest motorcycle market, where 231.712 motorcycles were registered in the first half of 2018 (an increase of 5.4\%). The next places are: France $(197,470$ motorcycles, +11.4\%), Spain (177,037 motorcycles, +10.7\%), Germany $(166,676$ motorcycles, $+6.8 \%)$ and the United Kingdom $(101,273$ motorcycles, $+0.9 \%)$ [2].
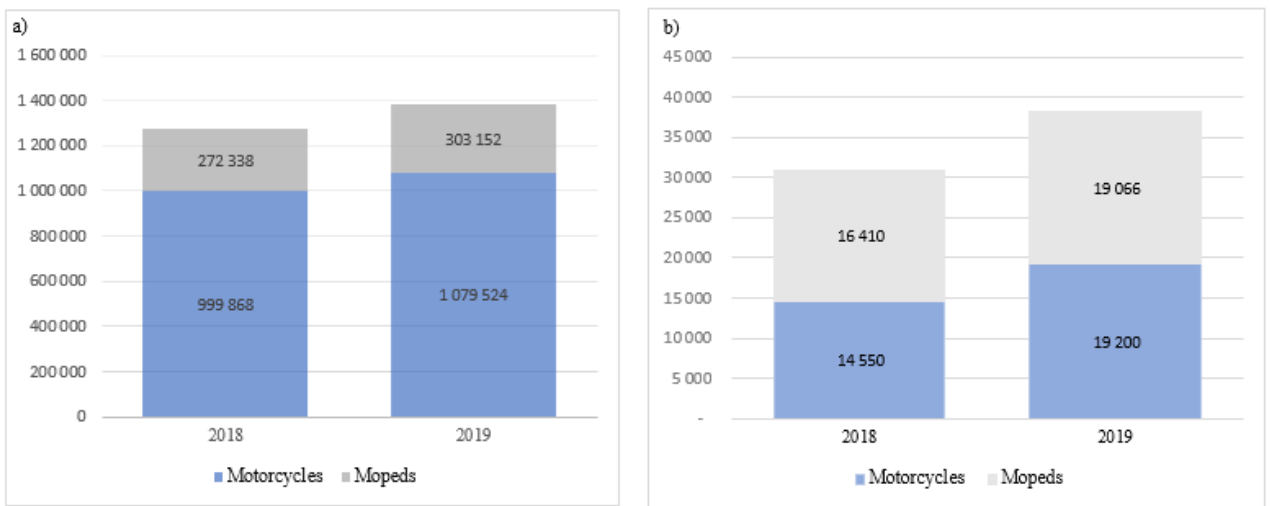

Fig. 1. Sales of motorcycles on the market of a) cumulative registrations of motorcycles and mopeds in the EU ICE + electric European Union, b) cumulative registrations of motorcycles and mopeds in the Poland ICE + electric [2]

The motorcycle sales market is stable and in the EU there are approximately 900,000 motorcycles registered annually in the period 2010-2017, while the potential of the Polish market is unstable, especially in recent years. After recording more than 2.5 times sales growth in 2015, and maintaining this level of sales in 2016, there was a decrease to over 15 thousand in 2017. However, in 2019 there was an increase in registered motorcycles compared to 2018 by over 4.5 thousand units [2].

When using motorcycles for recreational or tourist purposes, the driver often has to choose whether to go on a vacation by car or motorcycle. There is no common system on the market of transporting motorcycles behind a passenger car, which would solve the above problem. Therefore, drivers often use universal lightweight trailers with special handles mounted to transport motorcycles. Alternatively, for the transport of motorcycles, specially adapted commercial vehicles are used. The above examples are associated with significant purchase costs for the average motorcycle owner and there is also the problem of their storage. In order to meet the above-mentioned problems, the Science and Technology Park in Opole has developed a device for the transport of light vehicles, including motorcycles. This device, registered as a patent under the number PL 224395, has been protected by the Patent Office of the Republic of Poland. As part of this article, the authors analysed the proposed concepts of this solution dedicated to the transport of light motorcycles using the Design Thinking method.

\section{Methodology and design tools}

The methodology of the design of the transport device is based on the Design Thinking approach. According to the definition, Design Thinking is a systematic approach to the 
innovation process [3]. Figure 4 below shows a schematic diagram of the procedure for designing a transport device.

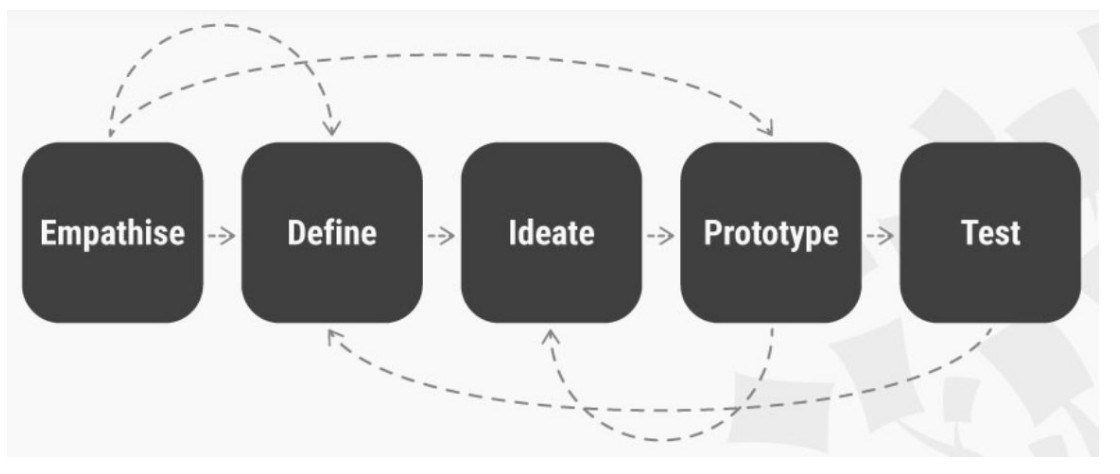

Fig. 2. The Design Thinking process [4]

In the further part of the work, individual blocks are described in detail - according to Fig. 4: the empathy and prototype stage, the problem definition stage, the idea generation stage and the testing stage.

\section{Empathise \& prototype}

The Design Thinking process starts with empathy. The first stage is a deep understanding of the user's needs and problems. For this purpose, the research team carried out research to identify the advantages and disadvantages of the patent-based prototype. Towing motorcycles by car is not a well-known and widely used solution for transporting motorcycles. The solution allowing for the mentioned method of transport, in which the motorcycle is towed by its front or rear axle, is mounted directly on the hook of the vehicle and is shown in the prototype version in the drawing (Fig. 2). The device allows to transport a motorcycle weighing up to $150 \mathrm{~kg}$ with its own weight up to $28 \mathrm{~kg}$. The advantage of this solution is the low purchase cost, ease of loading and storage. The device requires additional equipment in the form of transport belts stabilizing the towed motorcycle. Thanks to the mechanical or electric lifting of the front wheel, fastening of the motorcycle can be easily done by one person [1]. 

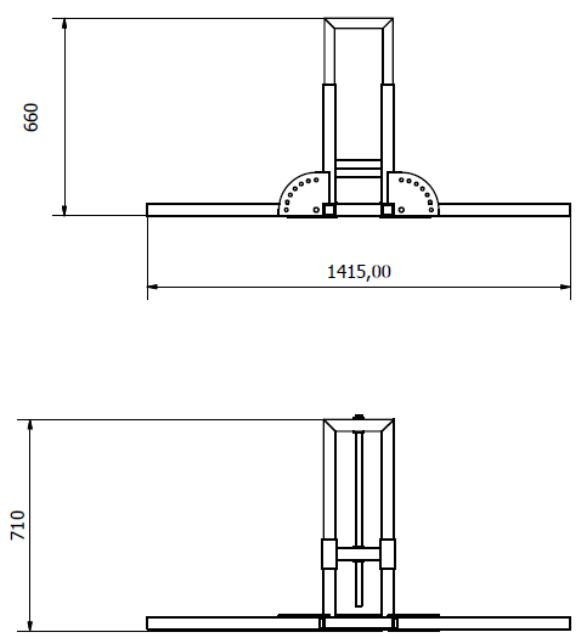
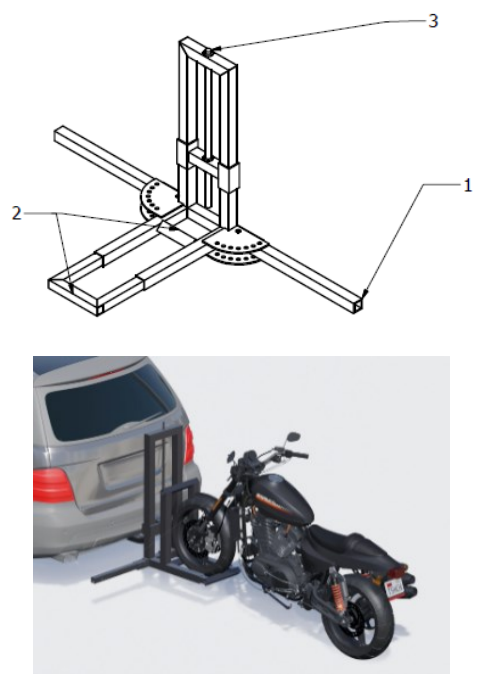

Fig. 3. Transport device based on patent PL 224395 B1 consisting of: (1) mounting holes, (2) wheel mounting beams, (3) trapezoidal screw

The method of transport consists of driving the front wheel of the motorcycle into the centre of the device (Fig. 2.) (between the beams (2)), securing the motorcycle with the belts (special places on the device (1)) and lifting the device to a given height - lifting can be done with crank and trapezoidal screw (3) or with an electric motor or a hydraulic cylinder.

The prototype concept is based directly on patent PL 224395 B1 and is made entirely of $40 \times 40 \times 3$ steel profiles. The concept also assumes a hitch on the hook that is inseparably connected with the entire device - hook mounting with four screws. The vertical movement (which enables the wheel to be raised from level 0 to level 1 for transport) is done by trapezoidal screw. The front wheel of the motorbike is located between two crossbars. This concept was made as Prototype 1, which is the benchmark for the next steps. Table 1. presents the problems that were observed in the research group along with possible solutions.

Table 1. Observed problems during the use of the prototype

\begin{tabular}{|l|l|}
\hline \multicolumn{1}{|c|}{ Problem } & \multicolumn{1}{c|}{ Solution } \\
\hline $\begin{array}{l}\text { Difficult fastening on the vehicle hook - } \\
\text { combined elements hindered easy } \\
\text { fastening }\end{array}$ & $\begin{array}{l}\text { Modular version of the transport device - } \\
\text { 1. Adapter for the hook } \\
\text { 2. Attaching the device to the adapter }\end{array}$ \\
\hline $\begin{array}{l}\text { The attachment was slipping on the hook - } \\
\text { Inaccurate design of the hitch assembly }\end{array}$ & $\begin{array}{l}\text { Performing a different method of } \\
\text { attachment to the hook and checking } \\
\text { possible movement around the hook axis. } \\
\text { Checking the possibility of adjusting the } \\
\text { angle of the mounting arms. }\end{array}$ \\
\hline $\begin{array}{l}\text { Locking of the towed vehicle lifting } \\
\text { mechanism during lifting }\end{array}$ & $\begin{array}{l}\text { Designing a different system for lifting the } \\
\text { front axle of the motorycle }\end{array}$ \\
\hline The weight of the device & Static analysis for various materials \\
\hline $\begin{array}{l}\text { In the event of possible rotation / slipping } \\
\text { of the device around the axis of the hook, } \\
\text { the arms may hit the car's bumper }\end{array}$ & $\begin{array}{l}\text { Making changes to the prototype in order } \\
\text { to check the optimal angle of the device } \\
\text { arms }\end{array}$ \\
\hline
\end{tabular}




\section{Defining the problem}

At this stage, the team synthesizes the information gathered during the Empathy Phase in order to define what the actual problem is.

Taking into account the above aspects, one of the most important factors determining the shape of the device is the load capacity of towing hooks of passenger vehicles and the mass of motorcycles (Table 2. Table 3.). These data determine the boundary conditions for the designed transport device in terms of its permissible mass, which will determine the permissible mass of the transported motorcycle. The review of motorcycle masses was done according to the categories in the Act on Vehicle Drivers [5].

Table 2. Classification of motorcycle vehicles [6]

\begin{tabular}{|c|c|}
\hline $\begin{array}{c}\text { Vehicle } \\
\text { classification }\end{array}$ & Category/subcategory name \\
\hline L1e & Lightweight two-wheeled motor vehicle \\
\hline \multicolumn{2}{|c|}{$\begin{array}{l}\text { - two wheels and propulsion according to Article } 4(3) \text {, and } \\
\text { - an engine capacity } \leq 50 \mathrm{~cm} 3 \text { if an internal combustion PI engine is part of the } \\
\text { propulsion configuration of the vehicle, and } \\
\text {-a maximum design speed } \leq 45 \mathrm{~km} / \mathrm{h} \text { and } \\
\text { - maximum continuous rated or net power }(1) \leq 4 \mathrm{~kW} \text { and } \\
\text { - maximum mass = technically permissible mass stated by the manufacturer }\end{array}$} \\
\hline L3e-A1 & Low performance motorcycle \\
\hline \multicolumn{2}{|c|}{$\begin{array}{l}\text { - engine capacity } \leq 125 \mathrm{~cm} 3 \text { and } \\
\text { - maximum continuous rated or net power }(1) \leq 11 \mathrm{~kW} \text { and } \\
\text { - power (1) / weight ratio } \leq 0.1 \mathrm{~kW} / \mathrm{kg}\end{array}$} \\
\hline L3e-A2 & Medium-performance motorcycle \\
\hline \multicolumn{2}{|c|}{$\begin{array}{l}\text { - maximum continuous rated or net power }(1) \leq 35 \mathrm{~kW} \text { and } \\
\text { - power }(1) / \text { weight ratio } \leq 0.2 \mathrm{~kW} / \mathrm{kg} \text { and } \\
\text { - it does not come from a vehicle equipped with an engine more than twice as powerful } \\
\text { (1), and } \\
\text { - L3e vehicle that cannot be classified on the basis of the additional criteria of sub- } \\
\text { classifications } 7,8 \text { and } 9 \text { of L3e-A1 vehicles }\end{array}$} \\
\hline $\mathbf{L 3 e}-\mathbf{A 3}$ & High-performance motorcycle \\
\hline- & lassified based on th \\
\hline
\end{tabular}

According to the conducted review, the mass of motorcycle vehicles in the L3e-A1 category may reach $190 \mathrm{~kg}$, in the L3e-A2 category up to $250 \mathrm{~kg}$, in the L3e-A3 category up to $390 \mathrm{~kg}$, which directly indicates that the final mass of the transportation device should be as low as possible. The mass of the transportation device was assumed to be reduced to $15 \mathrm{~kg}$, taking into account the prototype device made of s235 steel. 
Table 3. Overview of the weight of popular motorcycles

\begin{tabular}{|c|c|c|}
\hline Classif. & Motorcycle & $\begin{array}{c}\text { Mass } \\
{[\mathrm{kg}]}\end{array}$ \\
\hline \multirow{10}{*}{$\begin{array}{c}\text { L3e - } \\
\text { A1 }\end{array}$} & Honda MSX125 & 103 \\
\hline & Yamaha YZF-R125 & 138 \\
\hline & Honda XL 125V Varadero & 187 \\
\hline & Honda CBF 125 & 127 \\
\hline & Honda CBR $125 \mathrm{R}$ & 127.3 \\
\hline & Junak 121 & 110 \\
\hline & Junak 123 & 120 \\
\hline & Keeway RKS 125 & 117 \\
\hline & KTM Duke 125 & 132 \\
\hline & Yamaha YBR & 125 \\
\hline \multirow{13}{*}{$\begin{array}{c}\text { L3e - } \\
\text { A2 }\end{array}$} & Yamaha MT-03 & 192,4 \\
\hline & Bajaj Dominar 400 & 183 \\
\hline & BMW G 310 R & 164 \\
\hline & BMW G 310 GS & 170 \\
\hline & Suzuki DL 650 V-Strom & $213-220$ \\
\hline & Kawasaki Ninja 400] & 168 \\
\hline & Kawasaki Ninja 650 & 193 \\
\hline & Kawasaki W 800 & 217 \\
\hline & Honda VT750C Shadow & 246 \\
\hline & BMW G 650 GS & 193 \\
\hline & Suzuki Inazuma 250 & 183 \\
\hline & Yamaha XJ6 & 210 \\
\hline & Yamaha XT660Z Tenere & 206 \\
\hline \multirow{4}{*}{$\begin{array}{c}\text { L3e- } \\
\text { A3 }\end{array}$} & Yamaha FZR 600 & 208 \\
\hline & BMW K1200LT & 387 \\
\hline & Honda Goldwing GL1200 & 299 \\
\hline & Honda CBR600RR & 196 \\
\hline
\end{tabular}

\subsection{Mass criterion}

At this stage, the team focuses on generating as many possible solutions to the defined problem as possible.

\section{$\underline{\text { Permissible towbar load }}$}

Towing hooks - this is the generally accepted name of devices for coupling a towing vehicle, most often a passenger car or a delivery vehicle with a towed vehicle - a caravan or a cargo (luggage) trailer. Towing hooks mounted on passenger cars and vans up to $3500 \mathrm{~kg}$, as defined in Directive 94 [7]. According to the guidelines, the manufacturer specifies the maximum axial load $\mathrm{S}$ and the towing capacity $\mathrm{D}$ in accordance with Fig 4. 


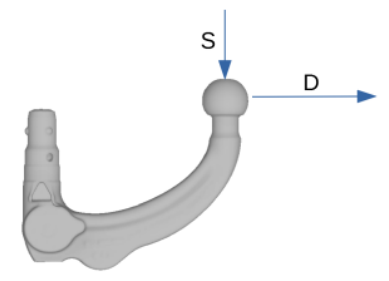

Fig. 4. Hook load in accordance with product data sheets [8]

Table 4. Load capacity of hooks of popular passenger vehicles [8]

\begin{tabular}{|c|c|c|c|c|}
\hline 、 & Model & Production date & $\begin{array}{c}\text { Vertical load S } \\
{[\mathrm{kg}]}\end{array}$ & $\begin{array}{c}\mathrm{D} \\
{[\mathrm{kN}]}\end{array}$ \\
\hline $\begin{array}{c}\text { Alfa } \\
\text { Romeo }\end{array}$ & Giulia & $2016-\ldots$ & 100 & 9,2 \\
\hline \multirow{8}{*}{ Audi } & A3 Sportback & $2008-2013$ & \multirow{5}{*}{100} & 9,7 \\
\hline & A6 Avant C7 & 2011-2018 & & 12,6 \\
\hline & A7 & $2010-\ldots$ & & 12,6 \\
\hline & A8 D3 /D4 & $\begin{array}{c}\text { 2002- } \\
\text { 2010/2010-2017 } \\
\end{array}$ & & $12,6-27,25$ \\
\hline & Q2 - Q5 (to 2016) & $2011-\ldots$ & & $12,6-22,5$ \\
\hline & Q5 & $2016-\ldots$ & 110 & 16,4 \\
\hline & Q7 & $2006-2015$ & 140 & 16,4 \\
\hline & Q7 & $2015-\ldots$ & 150 & 16,4 \\
\hline \multirow{7}{*}{ BMW } & 5 Series GT & $2009-\ldots$ & \multirow{4}{*}{100} & $11,9-15,5$ \\
\hline & $\begin{array}{c}5 \text { Series Touring } \\
\text { F11/F10 }\end{array}$ & $\begin{array}{c}2010- \\
2017 / 2010-2014 \\
\end{array}$ & & 11,8 \\
\hline & $\begin{array}{c}7 \text { Series sedan E65 / } \\
\text { F01 / F02 }\end{array}$ & $\begin{array}{c}2001-2008 /- \\
2015 /-\ldots . \\
\end{array}$ & & $15 / 17,5 / 12,15$ \\
\hline & X3 F25 / X4 F26 & 2010-/2014- & & 12 \\
\hline & X5 E53 / E70 / F15 & $\begin{array}{c}2000-2006 / 03- \\
13 / 13-. .\end{array}$ & 150 & $15,5 / 16 / 16$ \\
\hline & X6 E71 & $2008-2014$ & 140 & 16 \\
\hline & X6 F16 & $2014-$ & 150 & 16 \\
\hline \multirow{12}{*}{ VW } & Amarok & $2010-$ & 120 & 14,3 \\
\hline & Arteon & $2017-$ & 100 & 11,5 \\
\hline & Crafter van & $2006-$ & 150 & 17,2 \\
\hline & Eos & $2006-$ & \multirow{3}{*}{100} & 9,3 \\
\hline & $\begin{array}{c}\text { Golf } \\
\text { Cross/V1HB/Variant }\end{array}$ & $\begin{array}{c}2007-/ 08-12 / 09- \\
13 \\
\end{array}$ & & $9,3-9,4$ \\
\hline & Jetta III & $2005-2010$ & & 9,3 \\
\hline & LT van/bus & $\begin{array}{l}\text { 1995-2006/96- } \\
06\end{array}$ & 120 & $17,7 / 20,6$ \\
\hline & $\begin{array}{c}\text { Passat B8 } \\
\text { Variant/Sedan } \\
\end{array}$ & 2014 & \multirow[t]{2}{*}{100} & 11,5 \\
\hline & Sharan & $2010-$ & & 12,5 \\
\hline & Tiguan & $2015-$ & \multirow[b]{2}{*}{140} & 12 \\
\hline & Touareg I/II/III & $\begin{array}{c}2002-2014 /- \\
2017 /-\ldots \\
\end{array}$ & & 16,3 \\
\hline & Transporter T4 van & 1990-1993 & 100 & 12,9 \\
\hline
\end{tabular}


On the basis of the presented table (Table 4.), the load capacity of the hook in popular passenger vehicles is between 100 and $120 \mathrm{~kg}$. The possibility of loading with the vertical load of $150 \mathrm{~kg}$ occurs in the case of bus-type transport vehicles, e.g. VW Crafter.

\subsection{Identification tests - verification of loads}

Determination of the force acting on the device during standstill was performed on the test stand (Fig. 5.), for different levels of the motorcycle front wheel's high of the on the transport device. The tested object is Suzuki GSX-R 1100, which unladen weight is $221 \mathrm{~kg}$ [9]. Averaging, the force of $1 \mathrm{kN}$ acting along the vertical axis of the towing vehicle hook (vertical load S) was assumed for the simulation calculations.

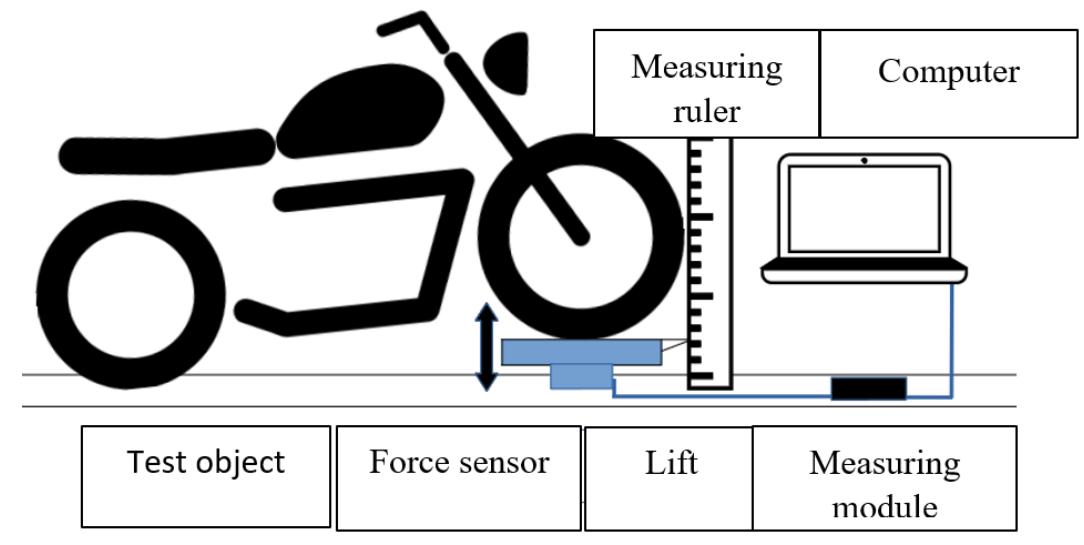

Fig. 5. Vertical force measuring station - diagram

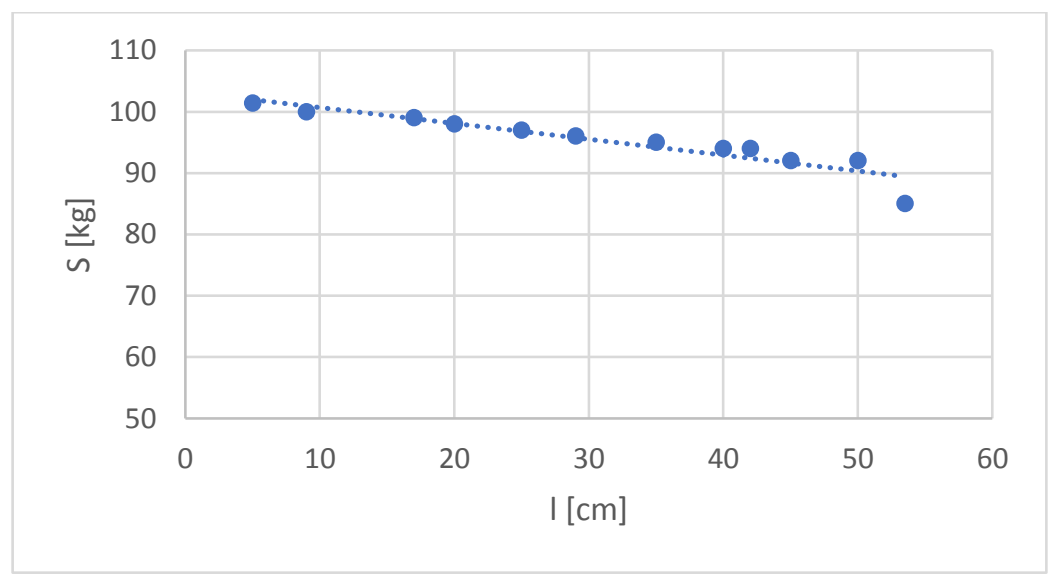

Fig. 6. The load on the transport device depending on the height of lifting the object.

Assuming the test vehicle's own weight of $221 \mathrm{~kg}$, the load on the device changed with the level of lifting the front wheel of the object. According to the obtained results (Fig. 6), the object wheel raised to the transport height (the height of the towing hook of the passenger vehicle) decreased by $9.5 \%$. 


\section{Generating ideas - Analysis of the structure of a motorcycle transport device}

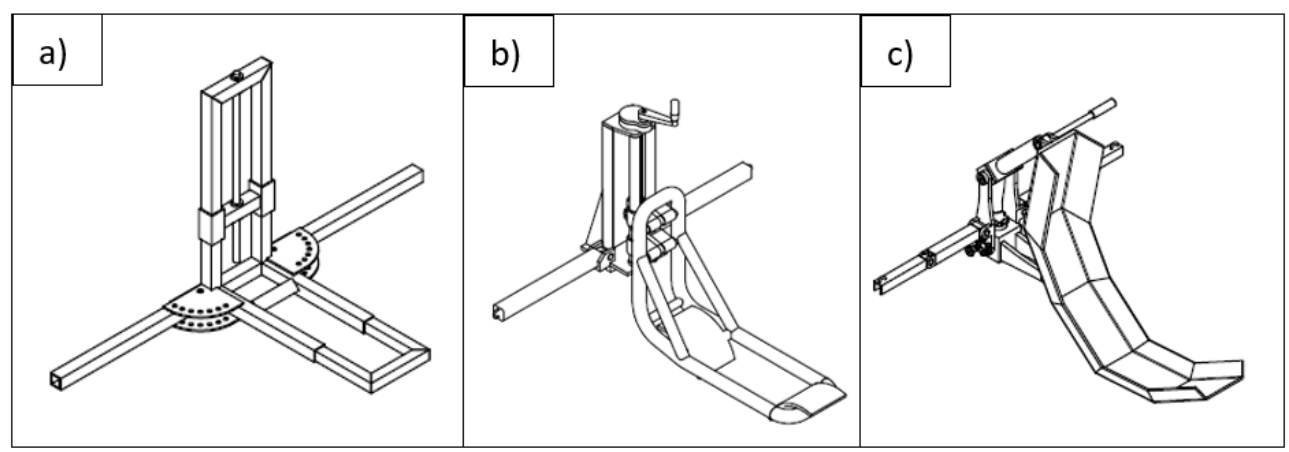

Fig. 7. Proposals for the construction of a transport device; a) concept 1, b) concept 2, c) concept 3

The analysis of the design was carried out from concept 1 (Fig. 7.a) - the prototype. Subsequent concepts (Fig. 7.) address two problems: lifting of the transported vehicle and reduction of the device weight. Concept 2 (Fig.7.b) improves the lifting of the towed vehicle by proposing circular linear guides and a trapezoidal screw with gear enabling installation of an additional motor. Another approach is concept 3 (Fig.7.c), which assumes the simplification of the components to reduce the weight of the product, as well as a changed approach to lifting the front wheel of the transported vehicle. This solution is based on rotating the profiled gutter around the main pin. The front wheel of the transported vehicle is lowered and raised using a turnbuckle.

On the basis of concepts 2 and 3, concept 4 has been created (Fig. 8.). It is distinguished by the simplification of the device frame elements, which facilitates the production process.

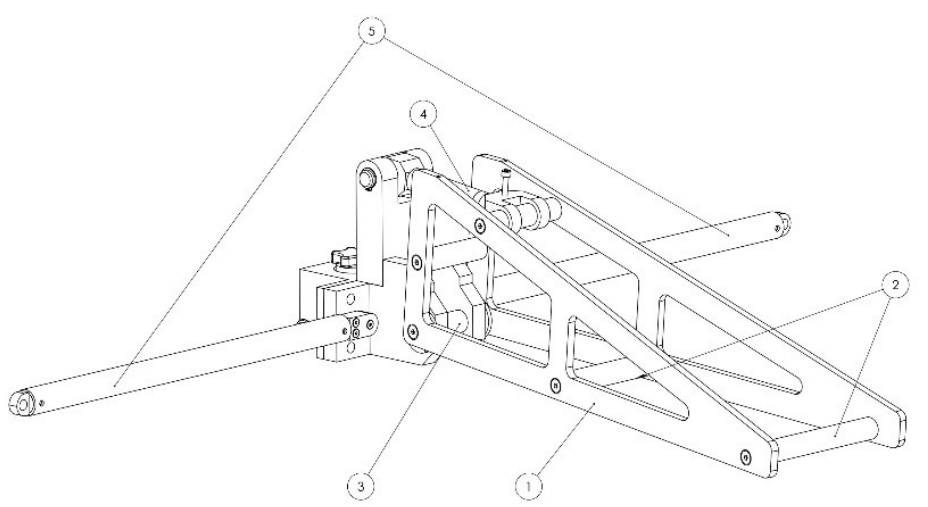

Fig. 8. Concept 4 consisting of: (1) elements made of $12 \mathrm{~mm}$ aluminium plate, (2) aluminium shafts, (3) main pin, (4) turnbuckle, (5) mounting arms

Concept 4 (Fig.8.) is mainly based on concept 3 (Fig.7.c). The mounting point for the front wheel of the towed vehicle is made of two aluminium elements (1) with a thickness of 12 mm connected by 4 aluminium shafts (2) and a main pin (3). The front wheel of the vehicle is lifted around the main pin (3) by means of a turnbuckle (4). The mounting arms (5) are made of aluminium tubes with the wall thickness of $2 \mathrm{~mm}$. 


\section{Test - analysis of construction}

In order to perform the simulation, each concept was prepared in SpaceClaim through simplifications enabling quick model verification. The bolts were reduced to their simplified counterparts and small details not affecting the analysis were omitted. The FEM analysis was carried out in the ANSYS Mechanical program.

Boundary conditions:

Confirmation in each of the three cases was set in the same way:

- Fixed support - at the point of installation on the vehicle hook

- Load imposed on the surface in the place where the motorcycle wheel is mounted $-1 \mathrm{kN}$

The simulations were carried out for concepts 1 and 4, assuming two different construction materials described in the table (Table 5.) [10].

Table 5. Mechanical properties of materials used in simulations

\begin{tabular}{|c|c|c|c|}
\hline Material & Aluminium 6081 & Steel S235 & Unit \\
\hline Young's modulus & 70000 & 200000 & $\mathrm{MPa}$ \\
\hline Poisson's Ratio & 0,3 & 0,3 & - \\
\hline Yield point & 270 & 235 & $\mathrm{MPa}$ \\
\hline Tensile strength & 310 & 460 & $\mathrm{MPa}$ \\
\hline
\end{tabular}

\subsection{FEM simulation results}

Results for static loading of device- concept 1 made of material: Steel S235 - mass $28 \mathrm{~kg}$.
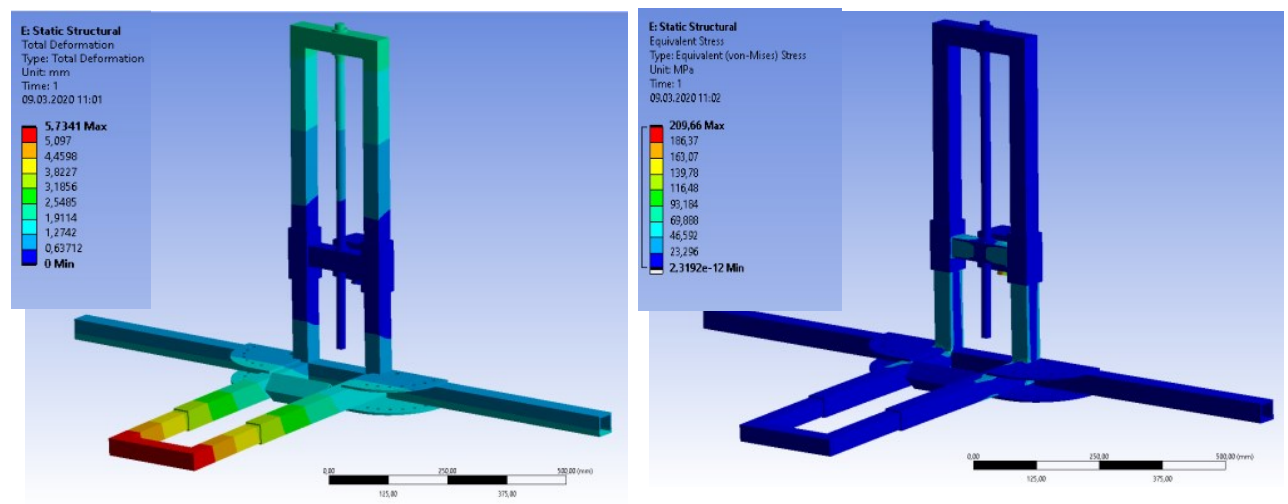

Fig. 9. Simulation results for concept 1 S235: total deformations, equivalent (von-Mises) Stress

Results for static load of device - concept 1 made of material: Aluminium 6081 - mass $13 \mathrm{~kg}$. 


\section{PRMR 2021}
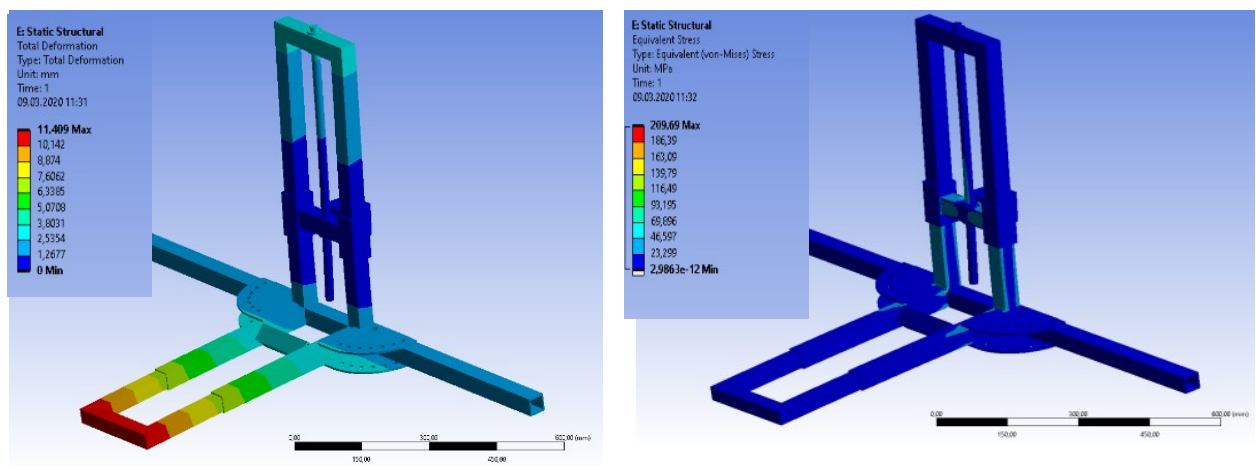

Fig. 10. Simulation results for concept 1 Aluminium 6081: total deformations, equivalent (von-Mises) Stress

Results for static load of device - concept 4 made of material: Steel S235 - mass $21 \mathrm{~kg}$
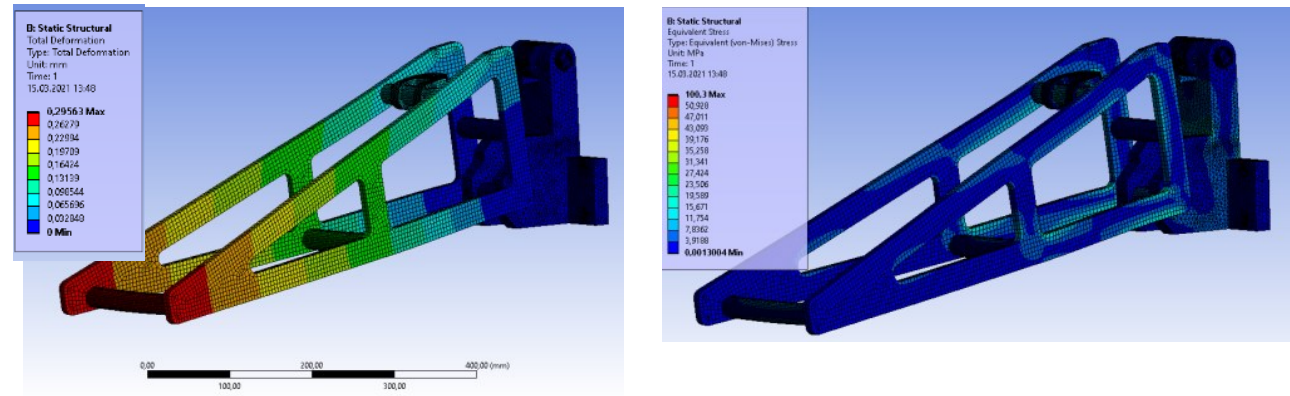

Fig. 11. Simulation results for Concept 4 S235: total deformations, equivalent (von-Mises) Stress Results for static load of device - concept 4 made of material : Steel S235 - mass $21 \mathrm{~kg}$
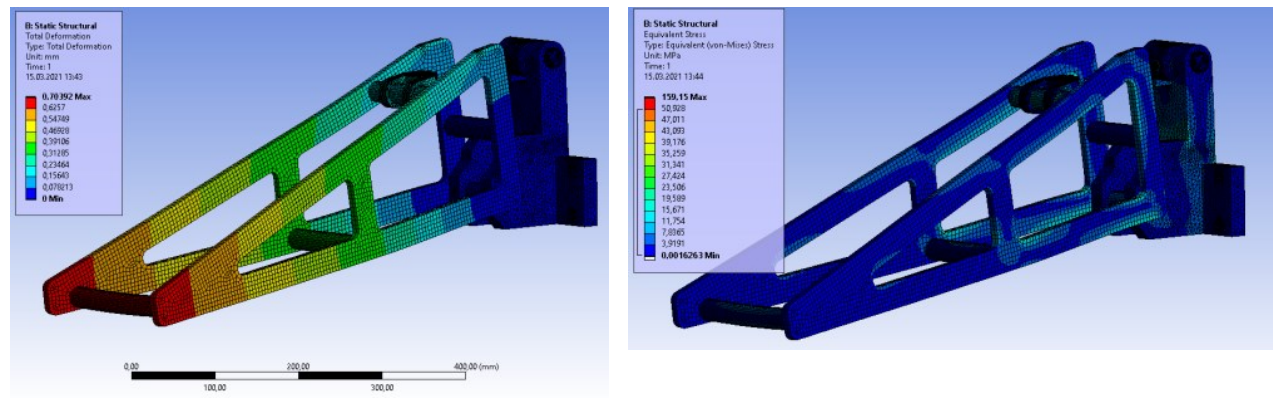

Fig. 12. Simulation results for Concept 4 Aluminium 6081: total deformations, equivalent (vonMises) Stress

The strength analyses carried out with the use of two different materials showed the maximum stresses and deformations for concepts 1 and 4 of the device. The maximum stresses in the structure for concept 1 for steel were: $140 \mathrm{MPa}$ at maximum deformations 5.7 mm (Fig.9.) and for aluminium $140 \mathrm{MPa}$ at deformations of $11.4 \mathrm{~mm}$ (Fig.10.), for steel 
concept 4, maximum stresses $100 \mathrm{MPa}$ (steel turnbuckle) with deformations of $0.3 \mathrm{~mm}$ (Fig.11.) and for the aluminium version, the stress of $159 \mathrm{MPa}$ (steel turnbuckle) with deformations of $0.7 \mathrm{~mm}$ (Fig.12).

\section{Summary}

The design process presented in this paper is based on the Design Thinking method. Firstly, the prototype was shown to motorcycle enthusiasts, showing that the patented invention aroused a lot of interest. However, in order to move from the prototype phase to the commercialization of the idea, the boundary conditions defined at the very beginning of the design must be met. The vertical force acting on the hook in case of a heavier motorcycle may vary from 100 to $110 \mathrm{~kg}$. The most important boundary condition is to meet the towing capacity guidelines of the tow vehicle. According to the table (Table 4.) in popular cars the vertical force acting on the hook should not exceed 100-120 kg. Meeting these guidelines determines the weight of the device, which should be within $10 \mathrm{~kg}$. Therefore, this paper presents an analysis only of the static load due to the weight of the towed vehicle.

For the presented boundary conditions, four proposals have been prepared: the first one is directly based on the patent, the second with the use of guides and the possibility of implementing an electric motor or hydraulic cylinder to lift the front axle of the motorcycle, and the third and fourth based on a change in the method of lifting the front axle of the motorcycle.

Table 6. Summary of the presented concepts

\begin{tabular}{|c|c|c|c|}
\hline Concept & $\begin{array}{l}\text { Steel version } \\
\text { Mass } \\
\text { kg }\end{array}$ & $\begin{array}{l}\text { Aluminium } \\
\text { alloy Mass } \\
\mathrm{kg}\end{array}$ & Prognosis \\
\hline 1 & 28 & 13 & $\begin{array}{l}\text { - Possibility to reduce weight and } \\
\text { improve lifting, }\end{array}$ \\
\hline 2 & 36 & 20 & $\mathrm{X}$ \\
\hline 3 & 23 & 12 & $\begin{array}{l}\text { - Solution changed to the next version - } \\
4\end{array}$ \\
\hline 4 & 21 & 11 & $\begin{array}{l}\text { - Possibility to reduce weight by } \\
\text { replacing selected components with other } \\
\text { materials - composites }\end{array}$ \\
\hline
\end{tabular}

The performed analysis of the load capacity of the passenger vehicle hook, as well as the weight of motorcycles in the appropriate classes, determines the motorcycle influences that are part of the possible transport through the proposed device:

- Class L3e-A1 - all motorcycles in the class,

- Class L3e-A2 - most of the motorcycles in the class (compliance with the load condition of the hook)

- Class L3e- A3 - selected motorcycles in the class (fulfilment of the load condition of the hook)

According to the table (Table 6.), guidelines (Table 2-4.), the weight of the device structure cannot exceed $15 \mathrm{~kg}$. Solution 1 (Fig. 7.a) and 4 (Fig. 8.), after introducing additional changes, promises the best chances of meeting both ergonomic and mass 
conditions. Solution 2 (Fig. 7.b) would significantly improve the quality of use of the device, but not meet the weight condition. The adopted material Aluminium 6081 for the structure allowed to significantly reduce the weight and is sufficient taking into account the adopted load conditions for this type of device.

The research was carried out as part of a project co-financed by the European Union from the European Regional Development Fund as part of the Regional Operational Program of the Opolskie Voivodeship for 2014-2020 1.1 Innovations in enterprises entitled: "BR works in the field of developing a technology for the implementation of an innovative ultralight transport device" decision no: RPOP.01.01.00-160007

\section{References}

1. J. Mamala, P. Kurowski, patent: PL224395 (B1) (2016)

2. ACEM statistical release, Motorcycles registrations in the European Union grew by $8 \%$ in 2019, ACEM report, Brussels, (11.02.2020)

3. S. J. Bell , A.L.A 39, 1/2; p. 44-49, (2008)

4. R. F. Dam, T. Y. Siang, 5 Stages in the Design Thinking Process [www.interactiondesign.org/literature/article/5-stages-in-the-design-thinking-process] (15.02.2021)

5. OJ L 227, p. 1-61, (28.08.2010)

6. OJ L 60, p. 52-128 (02.03.2013)

7. Z. Budniak, A.t.e.s.t R. 12, nr 5, p. 64-69, (2011)

8. www.ehaki.pl (15.12.2020)

9. www.gmoto.pl/motocykle/suzuki/gsx/1100/ (11.02.2021)

10. H.H. Lee, Finite Element Simulations with ANSYS Workbench 18, SDC Pub. (2018) 